\title{
Effect of Roasting Degree, Extraction Time, and Temperature of Coffee Beans on Anti-Hyperglycaemic and Anti-Hyperlipidaemic Activities Using Ultrasound-Assisted Extraction
}

\author{
Acharaporn Duangjai ${ }^{1}, K$ anittaporn Trisat ${ }^{2}$, and Surasak Saokaew ${ }^{3-6}$ \\ ${ }^{1}$ Unit of Excellence in Research and Product Development of Coffee, Division of Physiology, School of Medical Sciences, \\ ${ }^{3}$ Center of Health Outcomes Research and Therapeutic Safety (Cohorts), \\ ${ }^{4}$ Unit of Excellence on Clinical Outcomes Research and IntegratioN (UNICORN), \\ ${ }^{5}$ Unit of Excellence on Herbal Medicine, School of Pharmaceutical Sciences, and ${ }^{6}$ Division of Pharmacy Practice, \\ Department of Pharmaceutical Care, School of Pharmaceutical Sciences, University of Phayao, Phayao 56000, Thailand \\ ${ }^{2}$ Department of Pharmacy Practice and Center of Excellence for Innovation in Chemistry, Pharmacological Research Unit, \\ Faculty of Pharmaceutical Sciences, Naresuan University, Phitsanulok 65000, Thailand
}

\begin{abstract}
Coffee consumption has been linked to a low risk of metabolic syndrome. However, evidence supporting its anti-hyperglycaemic and anti-hyperlipidaemic activities remain poorly defined. The ultrasound-assisted extraction (UAE) technique has been shown to achieve high yields of bioactive compounds in coffee, with preserved functionality. The goal of the present study was to determine the effect of various coffee roasting extracts using UAE on their anti-hyperglycaemic and anti-hyperlipidaemic properties. We examined $\alpha$-amylase and $\alpha$-glucosidase, micelle size, micelle solubility, and pancreatic lipase activities. Coffee roasting degrees were classified as light coffee (LC), medium coffee (MC), and dark coffee (DC). We showed that $\mathrm{DC}$ at $80^{\circ} \mathrm{C}$ for $10 \mathrm{~min}, 40^{\circ} \mathrm{C}$ for $20 \mathrm{~min}$, and $20^{\circ} \mathrm{C}$ for $20 \mathrm{~min}$ has a high potency to inhibit $\alpha$-amylase, $\alpha$-glucosidase, and pancreatic lipase activities by $33.79 \pm 3.25 \%, 19.68 \pm 1.43 \%$, and $36.63 \pm 1.58 \%$, respectively. LC enhanced cholesterol micelle size and suppressed cholesterol micelle solubility, which suggests that coffee roasting may enhance anti-hyperglycaemic and anti-hyperlipidaemic activities.
\end{abstract}

Keywords: anti-hyperglycaemic, anti-hyperlipidaemic, arabica, coffee roasting, ultrasound-assisted extraction

\section{INTRODUCTION}

Currently, the prevalence of metabolic syndrome is rising worldwide. Metabolic syndrome is a group of several abnormalities, including hypertension, dyslipidaemia, obesity, hyperinsulinaemia, and hyperglycaemia, which are associated with cardiovascular disease and type 2 diabetes mellitus (Alberti et al., 2009). The first approach to manage metabolic syndrome is lifestyle modification, weight control, and physical activity, whereas medication is considered secondary (Grundy et al., 2004). The adverse effects of medication are often unpredictable and may result from drug therapy. Thus, alternative medications have gained attention, especially dietary supplements, vitamins, and herbal medicines (Nelson and Perrone, 2000). Several natural products, such as green tea catechins, Tiliacora triandra (Colebr.) Diels, Spirogyra ne- glecta, and $\alpha$-cyclodextrin, have been suggested due to their lipid-lowering properties (Furune et al., 2014; Duangjai et al., 2016; Kobayashi and Ikeda, 2017; Duangjai and Saokaew, 2019), whereas berries, blueberries, black currants, and blue honeysuckle fruits have been recommended for hyperglycaemia-lowering effects (CastroAcosta et al., 2016; Zhang et al., 2019).

Anthocyanin-rich plants have a low risk of inducing hyperlipidaemia since they inhibit pancreatic lipase and cholesterol esterase activities, and decrease cholesterol absorption by interfering with micellar solubility of cholesterol and micelle formation (Chamnansilpa et al., 2020). Additionally, anthocyanin can suppress increases in postprandial glucose levels by inhibiting carbohydratehydrolysing enzymes, $\alpha$-amylase, and $\alpha$-glucosidase (Gowd et al., 2017). Indeed, diets rich in polyphenols are associated with a low risk of cardiovascular disease and 
are recommended as an alternative treatment of dyslipidaemia (Annuzzi et al., 2014).

Polyphenolic extracts from vegetables may contribute to the management of hyperglycaemia, hyperlipidaemia, and hypertension through targeting $\alpha$-amylase, $\alpha$-glucosidase, pancreatic lipase, renin, and angiotensin-converting enzymes (Sultana et al., 2020). Virtual screening and molecular docking have revealed the potential of polyphenols to regulate carbohydrate metabolism and hyperglycaemia, in which caffeic acid, curcumin, cyanidin, daidzein, epicatechin, eriodyctiol, ferulic acid, hesperetin, naringenin, pinoresinol, quercetin, resveratrol, and syringic acid inhibit $\alpha$-glucosidase activity, while catechin, hesperetin, kaempferol, silibinin, and pelargonidin inhibit $\alpha$ amylase (Rasouli et al., 2017).

Coffee green bean and coffee roasting are powerful sources of bioactive ingredients, especially polyphenols, such as caffeine, chlorogenic acid, diterpenes, and trigonelline (Hu et al., 2019). Dietary polyphenols possess various biological properties, including antioxidant, antiapoptotic, anti-ageing, anticarcinogenic, anti-inflammatory, anti-atherosclerosis, and cardiovascular protective properties (Han et al., 2007). Previous studies have shown the ability of coffee consumption to lower the risk of obesity, metabolic syndrome, and type 2 diabetes (Nordestgaard et al., 2015; Shang et al., 2016). However, the role of different roasting degrees on the anti-hyperglycaemic and anti-hyperlipidaemic activities of coffee remains less evident. The ultrasound-assisted extraction (UAE) technique has been proposed as a green extraction technique for food and natural products that results in higher yields of bioactive compounds. This technique should accelerate the extraction process and preserve the functionality of bioactive compounds (Chemat et al., 2017; Quintero Quiroz et al., 2019; Kumar et al., 2021).

This study investigated the effect of different coffee roasting degrees on anti-hyperglycaemic and anti-hyperlipidaemic properties using UAE conditions. Anti-hyperglycaemic effects were examined by evaluating $\alpha$-amylase and $\alpha$-glucosidase inhibitory activities, while anti-hyperlipidaemic activity was measured by determining particle sizes of cholesterol micelles, micellar solubility of cholesterol, and pancreatic lipase activity.

\section{MATERIALS AND METHODS}

\section{Chemicals}

3,5-Dinitro salicylic acid (DNS), p-nitrophenyl butyrate $(p$-NPB), acarbose, $\alpha$-amylase, $\alpha$-glucosidase, ethylenediaminetetraacetic acid (EDTA), 3-(N-morpholino) propanesulfonic acid (MOPS), 4-nitrophenyl-D-glucopyranoside (pNPG) pancreatic lipase (type II, from porcine pancreas) phosphatidylcholine, cholesterol, and sodium tau- rocholate were purchased from Sigma-Aldrich Co. (St. Louis, MO, USA). All other chemical reagents used in this study were of analytical grade.

\section{Plant material}

Coffee beans were obtained from the Chao-Thai-Pukao Factory (Chiang Mai, Thailand). The voucher number of the coffee tree was NU003806 and it was deposited in the PNU herbarium of the Faculty of Biology, Naresuan University, Phitsanulok, Thailand. Different coffee roasting degrees were prepared using variations of roasting time and temperature $\left(10 \sim 20 \mathrm{~min}\right.$ and $176.7 \sim 232.2^{\circ} \mathrm{C}$, respectively), and classified as light coffee (LC), medium coffee (MC), and dark coffee (DC). Roasted coffee beans were extracted with water $(1: 5 ; \mathrm{w} / \mathrm{v})$ by using an ultrasonic bath operating at $35 \mathrm{kHz}$ at $80^{\circ} \mathrm{C}$ for 5,10 , and 20 min. Obtained extracts were dried using a freeze dryer (CoolSafe 110-4 Pro, LaboGene ${ }^{\mathrm{TM}}$, Allerød, Denmark). The coffee roasts extracts (LC, MC, and DC) were stored at $-20^{\circ} \mathrm{C}$.

\section{In vitro antidiabetic activity}

$\alpha$-Amylase inhibitor activity assays: $\alpha$-Amylase inhibition activity assay was carried out according to previous studies (Caraway, 1959; Kazeem et al., 2013), with minor modifications. A total of $100 \mu \mathrm{L}$ of $\alpha$-amylase was pre-incubated with $50 \mu \mathrm{L}$ of coffee roast extracts $(5 \mathrm{mg} / \mathrm{mL})$ or acarbose $(200 \mu \mathrm{M})$ at $37^{\circ} \mathrm{C}$ for $10 \mathrm{~min}$. Then, $100 \mu \mathrm{L}$ of starch $(2 \mathrm{mg} / \mathrm{mL})$ was added to initiate the reaction, and reactions were incubated at $37^{\circ} \mathrm{C}$ for $20 \mathrm{~min}$. Reactions were terminated by adding $100 \mu \mathrm{L}$ of $1 \%$ DNS, boiled for $5 \mathrm{~min}$, and the absorbance was measured at $540 \mathrm{~nm}$. $\alpha$-amylase inhibition activity was calculated as a percentage of the control.

$\alpha$-Glucosidase inhibitor activity assays: $\alpha$-Glucosidase inhibition activity assays were examined using the method by Quan et al. (2019), with slight modifications. Coffee roast extracts $(5 \mathrm{mg} / \mathrm{mL})$ or acarbose $(2 \mathrm{mM})$ were pre-incubated with $\alpha$-glucosidase solution [in $0.1 \mathrm{M}$ potassium phosphate buffer $\left(\mathrm{pH} \mathrm{7.0)]}\right.$ at $37^{\circ} \mathrm{C}$ for $15 \mathrm{~min}$. Then, $100 \mu \mathrm{L}$ of pNPG $(400 \mu \mathrm{M})$ was added to initiate the reaction, and the reaction was incubated at $37^{\circ} \mathrm{C}$ for $40 \mathrm{~min}$. Finally, $\mathrm{Na}_{2} \mathrm{CO}_{3}(0.1 \mathrm{M})$ was added to terminate the reaction and the absorbance was measured at $405 \mathrm{~nm}$. Inhibition was expressed as a percentage of control.

\section{In vitro lipid absorption}

Solubility studies of cholesterol micelles: Cholesterol micelle solutions were prepared according to the method of Kirana et al. (2005), with slight modification. Micelle solutions contained phosphatidylcholine $(0.6 \mathrm{mM})$, cholesterol $(1 \mathrm{mM})$, and sodium taurocholate $(1 \mathrm{mM})$. Coffee roast extracts $(100 \mu \mathrm{g} / \mathrm{mL})$ were added to the micelle solutions for $3 \mathrm{~h}$. Solutions were filtered using a $0.22 \mu \mathrm{m}$ 
filter, and the concentration of cholesterol in the filtrate was calculated as cholesterol micellar solubility using cholesterol assay kits.

Determination of cholesterol micelles particle sizes: Particle sizes of cholesterol micelles were determined according to the method of Kirana et al. (2005), with minor modification. Cholesterol micellar solutions were prepared from phosphatidylcholine, cholesterol, and sodium taurocholate, as per previous studies (Yamanashi et al., 2007; Duangjai et al., 2016). Coffee roast extracts $(100 \mu \mathrm{g} / \mathrm{mL})$ were incubated with cholesterol micellar solutions at $37^{\circ} \mathrm{C}$ for $3 \mathrm{~h}$, and particle sizes were determined using a particle size analyzer.

Pancreatic lipase inhibition assays: Pancreatic lipase inhibition studies were conducted according to the method of Kim et al. (2007), with slight modifications. Lipase activity was measured using $p$-NPB as a substrate. Porcine pancreatic lipase enzymes were prepared by reconstituting lipase in a buffer containing $10 \mathrm{mM}$ MOPS and 1 mM EDTA (pH 6.8) with $100 \mathrm{mM}$ Tris-HCL and $5 \mathrm{mM}$ $\mathrm{CaCl}_{2}$ (pH 7.0). Coffee roast extracts $(2.5 \mathrm{mg} / \mathrm{mL}$ ) or orlistat $(50 \mu \mathrm{M})$ were incubated with the enzyme solution at $37^{\circ} \mathrm{C}$ for $15 \mathrm{~min}$. Then, $10 \mathrm{mM} p$-NPB in dimethyl formamide was added and the reaction was incubated at $37^{\circ} \mathrm{C}$ for $30 \mathrm{~min}$. Hydrolysis of $p$-NPB to $p$-nitrophenol was measured at an absorbance $405 \mathrm{~nm}$. Inhibition of pancreatic lipase was calculated according to the follow-
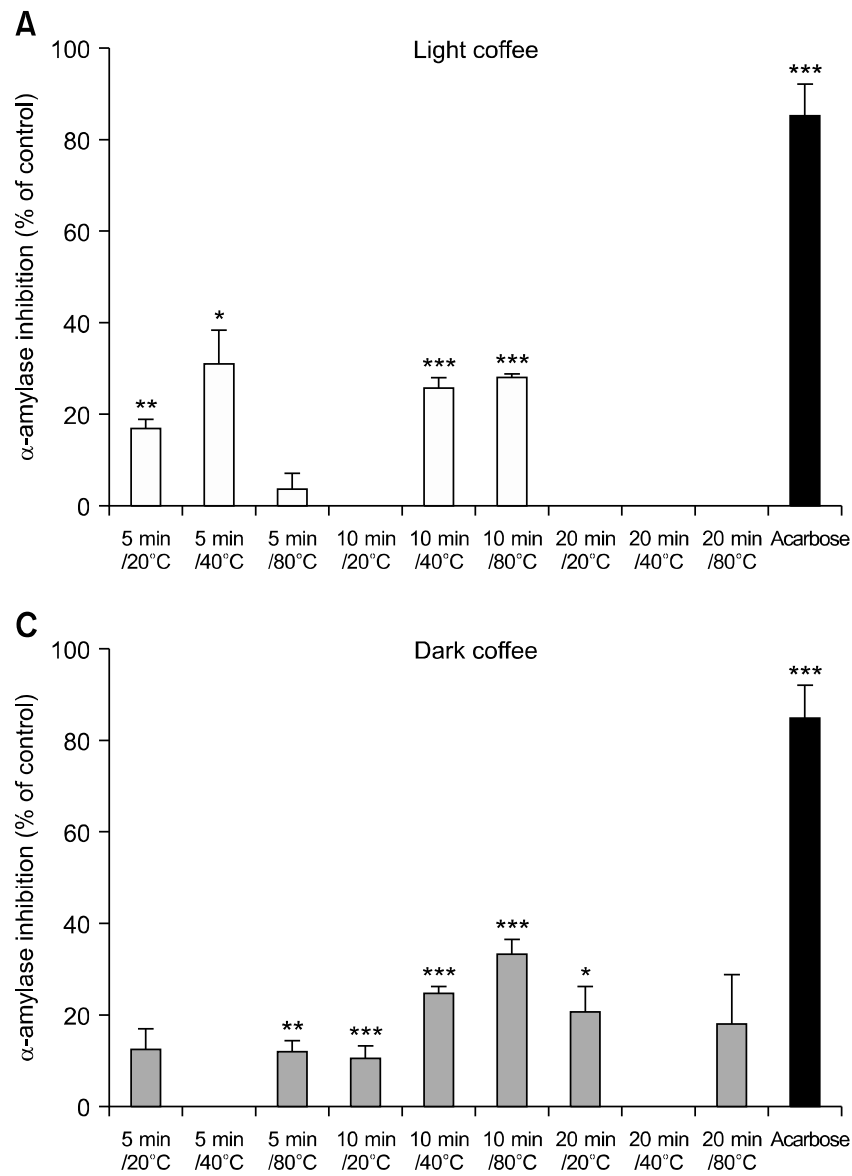

ing formula:

$\%$ pancreatic lipase inhibition $=$

$$
\frac{\left[\text { Absorbance }_{(\text {control })}-\text { Absorbance }_{(\text {sample })}\right]}{\text { Absorbance }_{(\text {control })}} \times 100
$$

\section{Statistical analyses}

Data were presented as mean \pm standard error of the mean (SEM). Evaluation of statistical significance was performed using paired two-tailed Student's $t$-tests, with $P \leq 0.05$ considered statistically significant.

\section{RESULTS}

\section{Effect of coffee roasting on antidiabetic activity}

To investigate the effect of coffee roasting using UAE on anti-hyperglycaemic properties, we examined inhibition of $\alpha$-amylase and $\alpha$-glucosidase activities. First, we determined inhibition of $\alpha$-amylase by coffee roasted at various extraction temperature $\left(20^{\circ} \mathrm{C}, 40^{\circ} \mathrm{C}\right.$, and $\left.80^{\circ} \mathrm{C}\right)$ for various times (5, 10, and $20 \mathrm{~min}$ ) (Fig. 1). At $5 \mathrm{mg} / \mathrm{mL}$, LC, MC, and DC have potential to inhibit $\alpha$-amylase activity, with strong inhibitory activities dependent on the extraction temperature and time. DC showed more potent inhibitory activity on $\alpha$-amylase than both LC and MC. $\mathrm{LC}$ at $20^{\circ} \mathrm{C}$ for $5 \mathrm{~min}, 40^{\circ} \mathrm{C}$ for $5 \mathrm{~min}$, and $80^{\circ} \mathrm{C}$ for

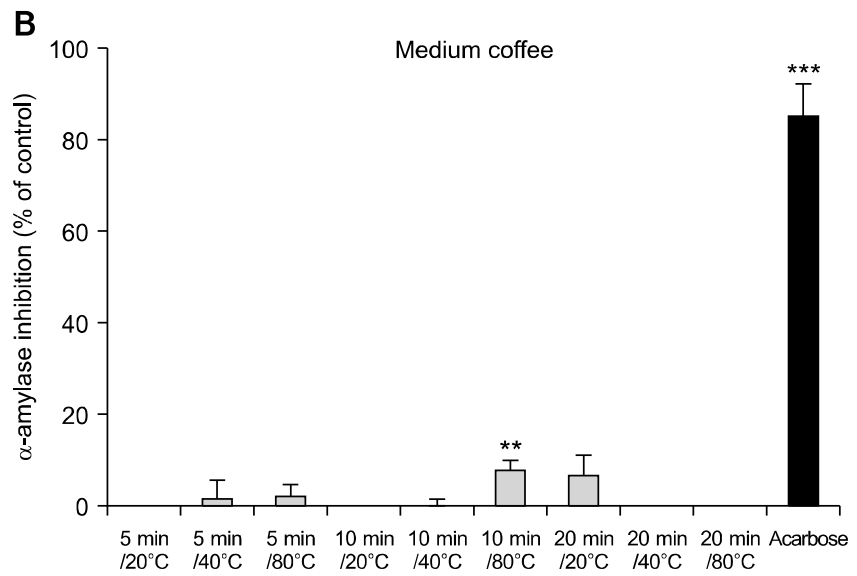

Fig. 1. Inhibition of the three types of coffee roasts against $\alpha$-amylase activity. Light coffee (LC), medium coffee (MC), and dark coffee (DC) at $5 \mathrm{mg} / \mathrm{mL}$ were used. Acarbose $(200 \mu \mathrm{M})$ was used as a standard inhibitor. Data show mean \pm SEM $(n=3)$. Significant differences vs. the control at ${ }^{*} P<0.05$, ${ }^{* *} P<0.01$, and ${ }^{* * *} P<0.001$. 
$10 \mathrm{~min}$, inhibited $\alpha$-amylase by $31.04 \pm 7.59 \%, 26.16 \pm$ $1.91 \%$, and $28.03 \pm 0.88 \%$, respectively. In comparison, $\mathrm{MC}$ at $80^{\circ} \mathrm{C}$ for $10 \mathrm{~min}$ inhibited $\alpha$-amylase by $7.95 \pm$ $1.96 \%$. Interestingly, $\mathrm{DC}$ at $80^{\circ} \mathrm{C}$ for $10 \mathrm{~min}$ demonstrated the highest inhibitory effect on $\alpha$-amylase (33.79 $\pm 3.25 \%$ ); however, DC exhibited lower activities than acarbose. Acarbose at $200 \mu \mathrm{M}(0.13 \mathrm{mg} / \mathrm{mL})$ (the positive control) inhibited $\alpha$-amylase by $85.33 \pm 6.94 \%$. This indicates that coffee roasting, especially DC, may inhibit $\alpha$-amylase activity.

Next, we observed the effect of roasting coffee at different extraction temperatures and times on $\alpha$-glucosidase activity, as shown in Fig. 2. DC at $40^{\circ} \mathrm{C}$ for $20 \mathrm{~min}$ strongly inhibited $\alpha$-glucosidase activity (19.68 $\pm 1.43 \%$ ), whereas $\mathrm{LC}$ at $20^{\circ} \mathrm{C}$ for $20 \mathrm{~min}$, and DC at both $80^{\circ} \mathrm{C}$ for $10 \mathrm{~min}$ and $20^{\circ} \mathrm{C}$ for $20 \mathrm{~min}$ only slightly inhibited $\alpha$-glucosidase activity (by $16.67 \pm 4.15 \%, 15.37 \pm 3.04 \%$, and $16.96 \pm 0.71 \%$, respectively). Acarbose at $200 \mu \mathrm{M}(1.29$ $\mathrm{mg} / \mathrm{mL}$ ) inhibited $\alpha$-glucosidase activity by $71.47 \pm 1.03 \%$. These data suggest that the different extraction temperatures and times of roasted coffee affects the inhibition of $\alpha$-glucosidase activity and, possibly, hyperglycaemia.

\section{Effect of coffee roasting on anti-hyperlipidaemic activity}

To assess the effect of coffee roasting at different extraction temperatures and times by UAE on anti-hyperlipidaemic activity, cholesterol micelle formation was esti-
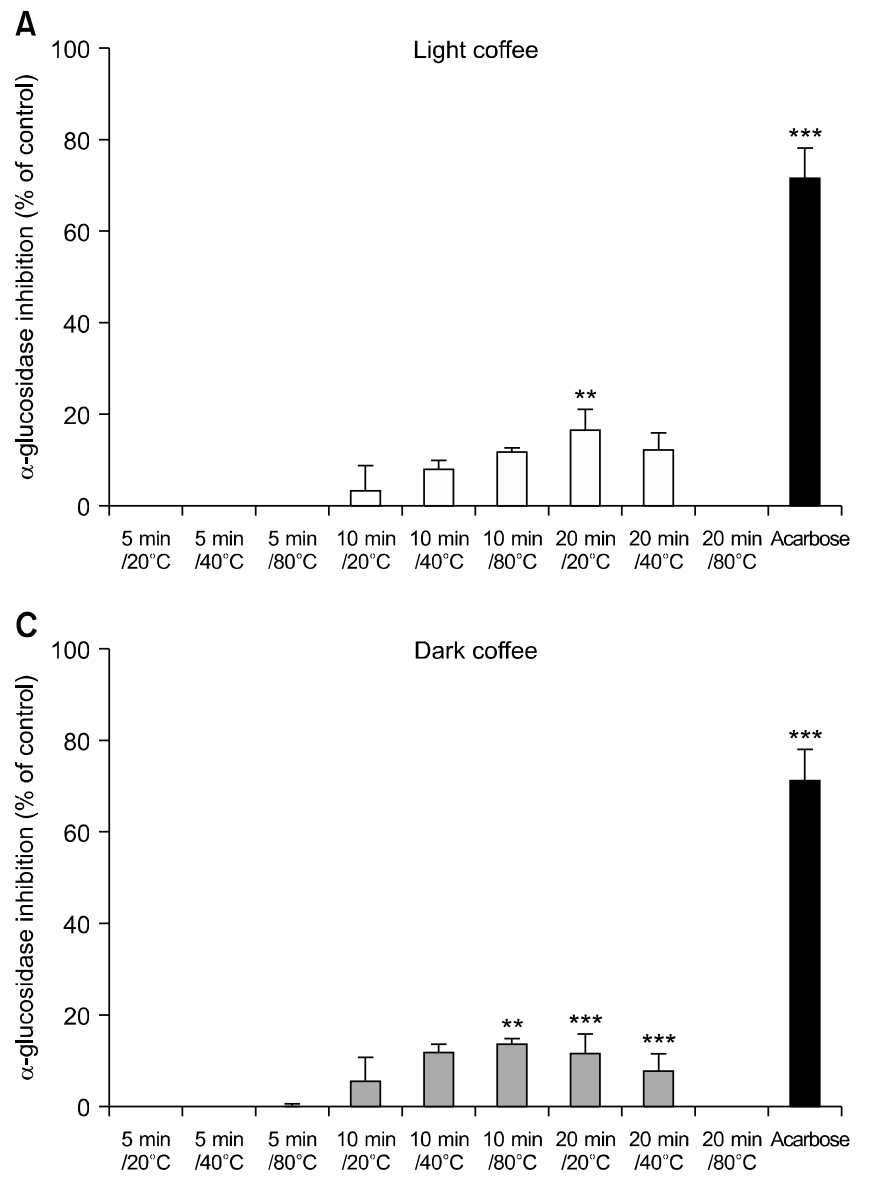

mated. First, the effect of coffee roasting on the size of cholesterol-mixed micelles was measured. All coffee roasting conditions increased particle sizes of the micelles compared with the control, with greater effects shown for LC than MC and DC (Fig. 3). The size of control cholesterol-mixed micelles was $124.98 \pm 6.40 \mathrm{~nm}$, whereas the particle size with LC were 381.96 1,372.67 $\mathrm{nm}$, with MC were $362.00 \sim 609.62 \mathrm{~nm}$, and with DC were $280.92 \sim 416.52 \mathrm{~nm}$. Remarkably, all extraction conditions of LC were effective in enhancing cholesterol micelle size, especially at $20^{\circ} \mathrm{C}$ for $5 \mathrm{~min}$ and $10 \mathrm{~min}$ (particles sizes of 1,372.67 $\pm 194.30 \mathrm{~nm}$ and 1,197.50 \pm $53.19 \mathrm{~nm}$, respectively). These data indicate that roasted coffee may have anti-hyperlipidaemic properties, acting via increasing the particle sizes of cholesterol micelles that influence cholesterol absorption.

Next, we assessed the effect of coffee roasting on cholesterol micelle solubility. Coffee roasting suppressed the solubility of cholesterol micelles (Fig. 4). LC and MC inhibited cholesterol micelle solubility to a greater extent than DC. LC suppressed solubility by $8.63 \sim 14.24 \%$, MC by $7.17 \sim 15.43 \%$, and DC by $4.80 \sim 8.45 \%$. Interestingly, LC at $20^{\circ} \mathrm{C}$ for $20 \mathrm{~min}$ and $\mathrm{MC}$ at $40^{\circ} \mathrm{C}$ for $10 \mathrm{~min}$ reduced solubility by $14.24 \pm 2.05 \%$ and $15.44 \pm 1.07 \%$, respectively. These data suggest that roasted coffee may have anti-hyperlipidaemic properties, acting via decreasing cholesterol micelle solubility, which inhibits choles-

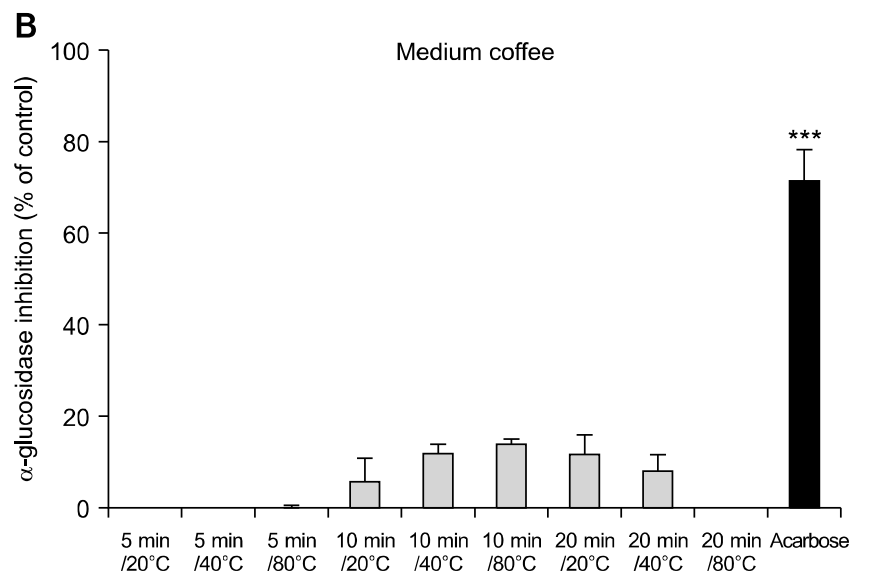

Fig. 2. Inhibition of the three types of coffee roasts against $\alpha$-glucosidase activity. Light coffee (LC), medium coffee (MC), and dark coffee (DC) at $5 \mathrm{mg} / \mathrm{mL}$ were used. Acarbose (2 mM) was used as a standard inhibitor. Data show mean \pm SEM $(n=3)$. Significant differences vs. the control at ${ }^{*} P<0.05$, ${ }^{* *} P<0.01$, and ${ }^{* * *} P<0.001$. 
A
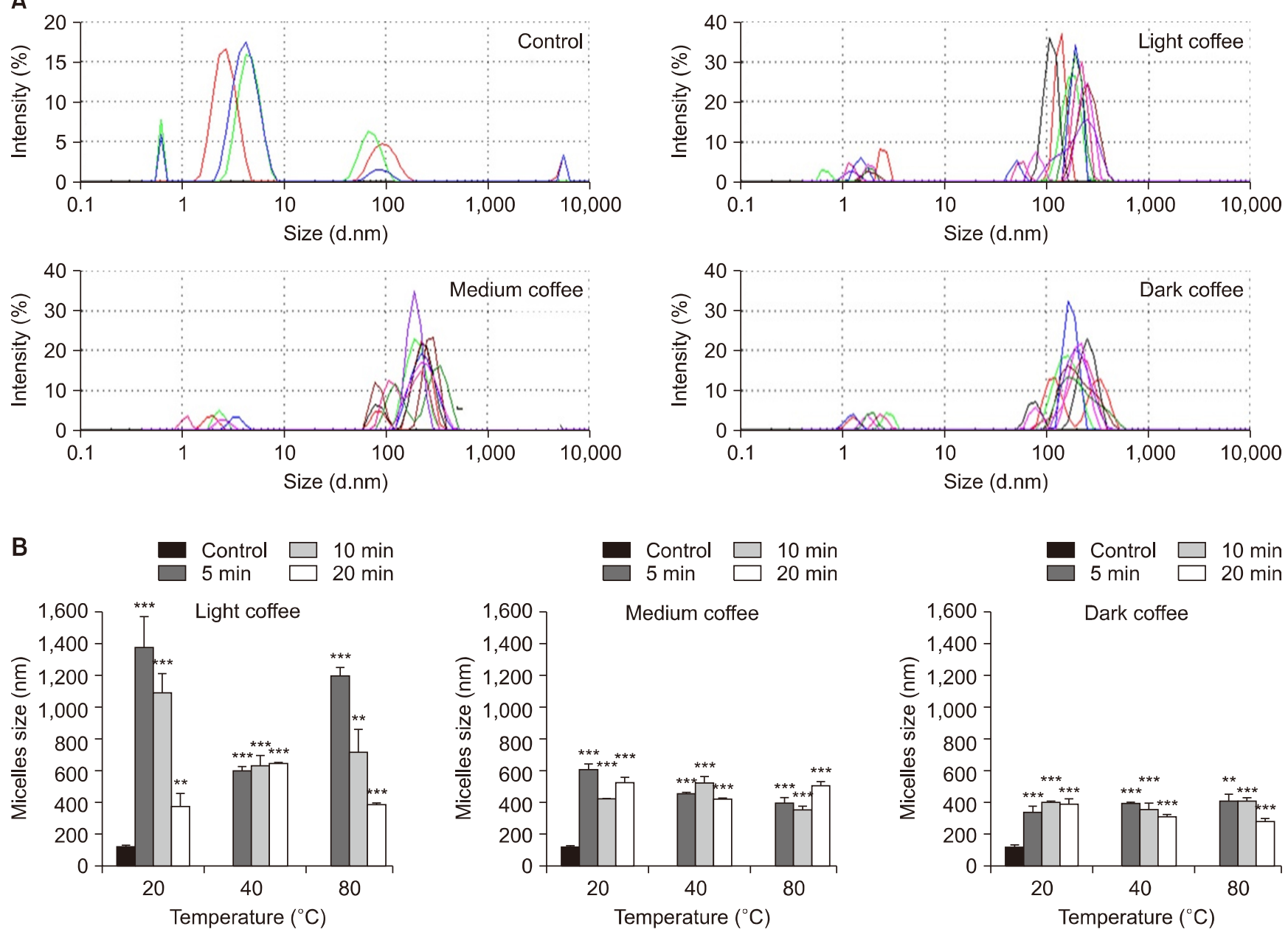

Fig. 3. Effect of the three types of coffee roasts on micelle sizes. Light coffee (LC), medium coffee (MC), and dark coffee (DC) at $100 \mu \mathrm{g} / \mathrm{mL}$ were incubated with mixed micelle solutions. (A) Scattering intensity of micelle size. (B) Micelle size formation. Data show mean $\pm \operatorname{SEM}(\mathrm{n}=3)$. Significant differences vs. the control at ${ }^{*} P<0.05$, ${ }^{* *} P<0.01$, and ${ }^{* * *} P<0.001$.
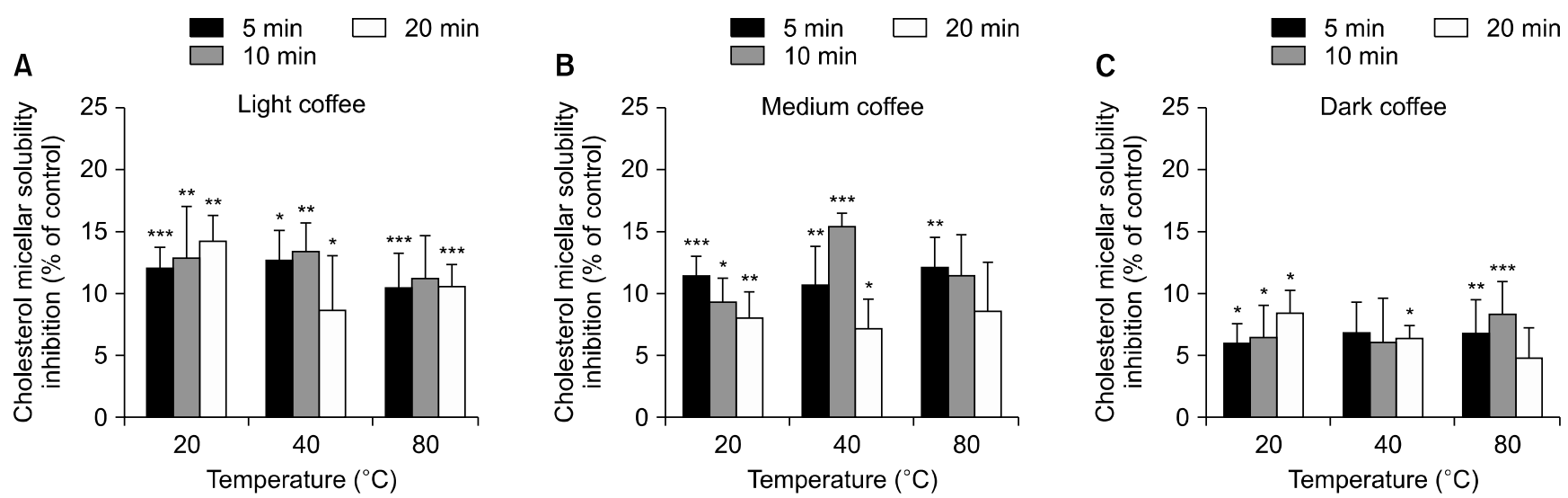

Fig. 4. Inhibition of cholesterol micellar solubility by the three types of coffee roasts. Light coffee (LC), medium coffee (MC), and dark coffee (DC) at $100 \mu \mathrm{g} / \mathrm{mL}$ were incubated with cholesterol micelle solutions. Data are presented as a \% of the control and show mean $\pm \operatorname{SEM}(\mathrm{n}=3)$. Significant differences vs. the control at ${ }^{*} P<0.05,{ }^{* *} P<0.01$, and ${ }^{* * *} P<0.001$.

terol absorption.

Finally, we determined the effect of coffee roasting on pancreatic lipase activity. At $2.5 \mathrm{mg} / \mathrm{mL}$, roasting inhibited pancreatic lipase activity of coffee (Fig. 5). DC inhibited the activity of pancreatic lipase to a greater extent than MC and LC. DC inhibited pancreatic lipase by 23.94 $\sim 36.63 \%$, MC by $23.51 \sim 29.26 \%$, and LC by $20.39 \sim$ $27.43 \%$. Interestingly, DC at $20^{\circ} \mathrm{C}$ for $20 \mathrm{~min}$ showed the highest ability to inhibit pancreatic lipase activity (36.63 $\pm 1.58 \%)$. Orlistat at $50 \mu \mathrm{M}$ was used as a positive con- 

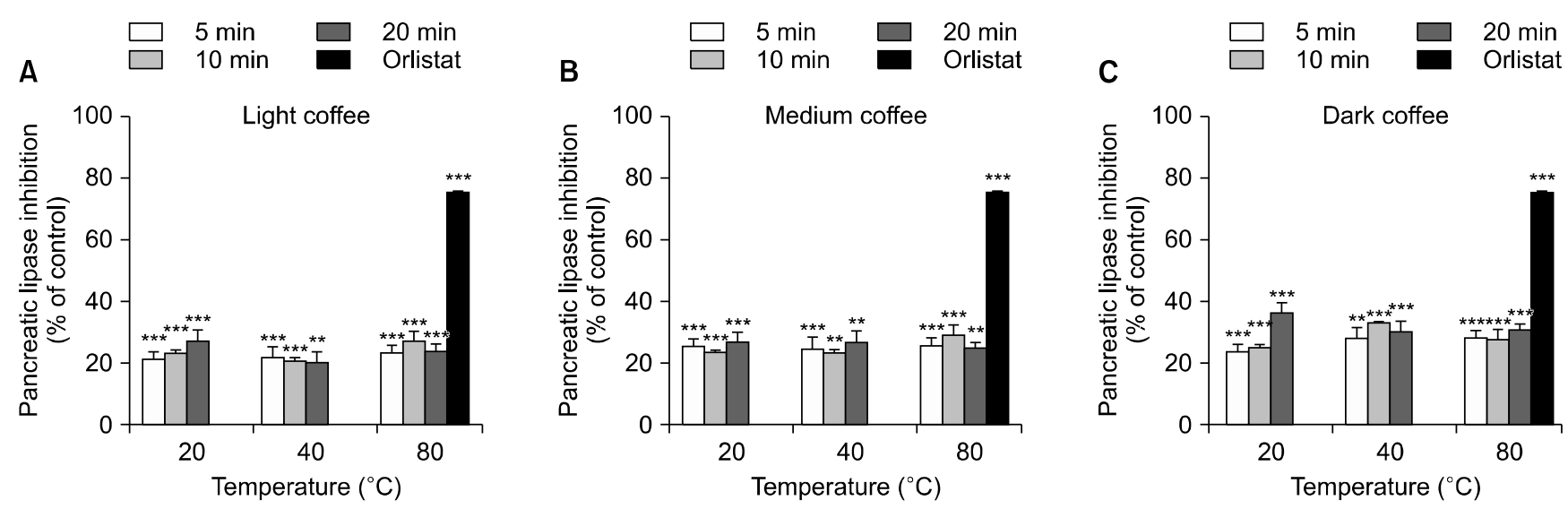

Fig. 5. Effect of the three types of coffee roasts on inhibition of pancreatic lipase activity. Orlistat was used as a positive control. Light coffee (LC), medium coffee (MC), and dark coffee (DC) $(2.5 \mathrm{mg} / \mathrm{mL})$ at extraction times 5,10 , and 20 min or orlistat (50 $\mu \mathrm{M})$ were incubated with pancreatic lipase and $p-\mathrm{NPB}$, and $\mathrm{p}$-nitrophenol production was measured. Data are presented as a $\%$ of the control and show mean EM $(\mathrm{n}=3)$. Significant differences vs. the control at ${ }^{*} P<0.05,{ }^{* *} P<0.01$, and ${ }^{* * *} P<0.001$.

trol, and inhibited pancreatic lipase activity by $75.57 \pm$ $0.42 \%$. These data suggest that roasted coffee may inhibit lipid digestion and demonstate anti-hyperlipidaemic effects via inhibiting pancreatic lipase activity.

\section{DISCUSSION}

UAE is a recognized technique for the extraction of phenolic compounds from plants for use in food composition. This study investigated the effects of coffee roasting with different roasting degrees using UAE on antihyperglycaemic and anti-hyperlipidaemic activities. We evaluated the effect of roasted coffee on $\alpha$-amylase and $\alpha$-glucosidase inhibition, cholesterol micelle size, micellar solubility of cholesterol, and pancreatic lipase activity. During coffee roasting, coffee beans undergo many reactions that alter their chemical and physical compositions, and change the physiological effects of coffee (Pittia et al., 2001; Noor Aliah et al., 2015; Choi et al., 2018). We analyzed coffee roasted to light, medium, and dark degrees. $\alpha$-Amylase and $\alpha$-glucosidase may be involved in carbohydrate digestion, glucose uptake, and regulating blood sugar levels. Inhibition of $\alpha$-amylase and $\alpha$-glucosidase are therapeutic approaches against hyperglycaemia (van de Laar et al., 2005; Gulati et al., 2012). Our results indicated that roasted coffee (LC, MC, and DC) has potential effects against hyperglycaemia by inhibiting $\alpha$-amylase and $\alpha$-glucosidase activities, with the greatest inhibitory activity shown for DC. Our findings are consistent with previous studies showing that the degree of coffee roasting affects $\alpha$-glucosidase activity (i.e., very dark roasted coffee extracts are more effective than dark and medium coffee extracts) (Alongi and Anese, 2018). However, while we showed that medium roasted coffee exhibited higher $\alpha$-glucosidase inhibitory activity, in a previous study no differences were shown among coffees roasted to different degrees (Alongi et al., 2021). The biological properties depend on the balance of the compounds formed and degraded during the roasting process (Vignoli et al., 2014). It was possible that altering functional properties of roasting is associated with changes to the bioactive compounds of coffee during roasting. In addition, activity depended on the extraction temperature and time of UAE. In another study, extraction parameters were suggested to alter anti-hyperglycaemic activities, in which optimum conditions (temperature, time, and $\mathrm{v} / \mathrm{w}$ ratio) were more effective in creating coffee that inhibits $\alpha$-amylase and $\alpha$-glucosidase activities (Liu et al., 2015). Other studies have demonstrated that extraction temperature affects the chemical compositions and capabilities of carbohydrate digestionrelated lipase inhibitory activities of extracts (Chen et al., 2016; Liu et al., 2017).

To clarify the effect of coffee roasting using UAE on anti-hyperlipidaemic ability, disturbance of cholesterol micelle formation and pancreatic lipase activity was examined. Pancreatic lipase plays a crucial role in lipid digestion, and pancreatic lipase inhibition reduces lipid absorption and blood lipid levels (Liu et al., 2020). In addition, cholesterol-mixed micelles play a vital role in enhancing intestinal lipid absorption (Woollett et al., 2006). Thus, inhibition of enzymes involved in lipid digestion and/or interference of cholesterol micelle formation may reduce the risk of developing anti-hyperlipidaemia. Our results indicate that roasting coffee induces anti-hyperlipidaemic properties by increasing micelle size and suppressing micelle solubility. LC increased particle size to a greater extent than both MC and DC, and both LC and MC inhibited cholesterol micelle solubility to a greater extent than DC. Coffee exhibited a hypocholesterolaemic effect as their soluble fibers and lipid content reduced cholesterol solubility, which affected the capacity to sequester bile salts from the micelle solution and ag- 
gregate to bigger sizes (Coreta-Gomes et al., 2020). Furthermore, roasting coffee induced anti-hyperlipidaemic effects on inhibiting lipid digestion, with DC reduced pancreatic lipase activity to a greater extent than $\mathrm{MC}$ and LC. Indeed, coffee polyphenols have been shown to suppress postprandial hyperglycaemia, hyperinsulinaemia, and hyperlipidaemia by inhibiting maltase, sucrase, and pancreatic lipase activities (Murase et al., 2012).

In conclusion, the findings of this study show that coffee roasted to different degrees using UAE possess antihyperglycaemic and anti-hyperlipidaemic properties via inhibition of $\alpha$-amylase, $\alpha$-glucosidase, and pancreatic lipase activities, and disturbing the particle size and solubility of cholesterol micelles. DC showed the highest inhibitory activity on $\alpha$-amylase, $\alpha$-glucosidase, and pancreatic lipase, whereas LC showed the greatest ability to interfere with micelle formation. This study is helpful for understanding the impact of extraction processes (temperature and time) and the resultant roasting degree on biological processes. Our study provided evidence of the optimal conditions of UAE for coffee roasting for its potential use as dietary supplement for treatment and prevention of hyperglycaemic and hyperlipidaemic. However, these results were obtained in in vitro studies, and further studies on cells and/or in vivo animal models are required.

\section{ACKNOWLEDGEMENTS}

We would like to thank the School of Medical Sciences, University of Phayao for providing the facilities to conduct the research. Financially supported by Unit of Excellence in Research and Product Development of Coffee (UoE63004), University of Phayao, Thailand.

\section{FUNDING}

This research was partially supported by Unit of Excellence in Research and Product Development of Coffee (UoE63004), (UoE64002), Unit of Excellence on Clinical Outcomes Research and IntegratioN (UNICORN) (FF64UoE003), School of Pharmaceutical Sciences, University of Phayao. and the NSTDA Chair Professor Grant (the Fourth Grant) of the Crown Property Bureau Foundation and the National Science and Technology Development Agency to Professor Dr. Vatcharin Rukachaisirikul. The funding source had no role in the study design, collection, analysis, and interpretation of data.

\section{AUTHOR DISCLOSURE STATEMENT}

The authors declare no conflict of interest.

\section{AUTHORS CONTRIBUTIONS}

$\mathrm{AD}$ contributed to designing the study. AD and KT prepared and edited the manuscript. All authors read and confirmed the manuscript.

\section{REFERENCES}

Alberti KG, Eckel RH, Grundy SM, Zimmet PZ, Cleeman JI, Donato KA, et al. Harmonizing the metabolic syndrome: a joint interim statement of the International Diabetes Federation Task Force on Epidemiology and Prevention; National Heart, Lung, and Blood Institute; American Heart Association; World Heart Federation; International Atherosclerosis Society; and International Association for the Study of Obesity. Circulation. 2009. 120:1640-1645.

Alongi M, Anese M. Effect of coffee roasting on in vitro $\alpha$-glucosidase activity: inhibition and mechanism of action. Food Res Int. 2018. 111:480-487.

Alongi M, Celayeta JMF, Vriz R, Kinsella GK, Rulikowska A, Anese M. In vitro digestion nullified the differences triggered by roasting in phenolic composition and $\alpha$-glucosidase inhibitory capacity of coffee. Food Chem. 2021. 342:128289. https:// doi.org/10.1016/j.foodchem.2020.128289

Annuzzi G, Bozzetto L, Costabile G, Giacco R, Mangione A, Anniballi G, et al. Diets naturally rich in polyphenols improve fasting and postprandial dyslipidemia and reduce oxidative stress: a randomized controlled trial. Am J Clin Nutr. 2014. 99: 463-471.

Caraway WT. A stable starch substrate for the determination of amylase in serum and other body fluids. Am J Clin Pathol. 1959. 32:97-99.

Castro-Acosta ML, Lenihan-Geels GN, Corpe CP, Hall WL. Berries and anthocyanins: promising functional food ingredients with postprandial glycaemia-lowering effects. Proc Nutr Soc. 2016. 75:342-355.

Chamnansilpa N, Aksornchu P, Adisakwattana S, Thilavech T, Mäkynen K, Dahlan W, et al. Anthocyanin-rich fraction from Thai berries interferes with the key steps of lipid digestion and cholesterol absorption. Heliyon. 2020. 6:e05408. https://doi. org/10.1016/j.heliyon.2020.e05408

Chemat F, Rombaut N, Sicaire AG, Meullemiestre A, FabianoTixier AS, Abert-Vian M. Ultrasound assisted extraction of food and natural products. Mechanisms, techniques, combinations, protocols and applications. A review. Ultrason Sonochem. 2017. 34:540-560.

Chen PH, Weng YM, Yu ZR, Koo M, Wang BJ. Extraction temperature affects the activities of antioxidation, carbohydrate-digestion enzymes, and angiotensin-converting enzyme of Pleurotus citrinopileatus extract. J Food Drug Anal. 2016. 24:548555.

Choi S, Jung S, Ko KS. Effects of coffee extracts with different roasting degrees on antioxidant and anti-inflammatory systems in mice. Nutrients. 2018. 10:363. https://doi.org/10.3390/ nu10030363

Coreta-Gomes FM, Lopes GR, Passos CP, Vaz IM, Machado F, Geraldes CFGC, et al. In vitro hypocholesterolemic effect of coffee compounds. Nutrients. 2020. 12:437. https://doi.org/ 
10.3390/nu12020437

Duangjai A, Limpeanchob N, Trisat K, Amornlerdpison D. Spirogyra neglecta inhibits the absorption and synthesis of cholesterol in vitro. Integr Med Res. 2016. 5:301-308.

Duangjai A, Saokaew S. Inhibitory effects of Tiliacora triandra (Colebr.) Diels on cholesterol absorption. J Complement Integr Med. 2019. 16:20170169. https://doi.org/10.1515/jcim-20170169

Furune T, Ikuta N, Ishida Y, Okamoto H, Nakata D, Terao K, et al. A study on the inhibitory mechanism for cholesterol absorption by $\alpha$-cyclodextrin administration. Beilstein J Org Chem. 2014. 10:2827-2835.

Gowd V, Jia Z, Chen W. Anthocyanins as promising molecules and dietary bioactive components against diabetes - a review of recent advances. Trends Food Sci Technol. 2017. 68:1-13.

Grundy SM, Hansen B, Smith SC Jr, Cleeman JI, Kahn RA; American Heart Association; National Heart, Lung, and Blood Institute; American Diabetes Association. Clinical management of metabolic syndrome: report of the American Heart Association/National Heart, Lung, and Blood Institute/American Diabetes Association conference on scientific issues related to management. Arterioscler Thromb Vasc Biol. 2004. 24:e19e24.

Gulati V, Harding IH, Palombo EA. Enzyme inhibitory and antioxidant activities of traditional medicinal plants: potential application in the management of hyperglycemia. BMC Complement Altern Med. 2012. 12:77. https://doi.org/10.1186/ 1472-6882-12-77

Han X, Shen T, Lou H. Dietary polyphenols and their biological significance. Int J Mol Sci. 2007. 8:950-988.

Hu GL, Wang X, Zhang L, Qiu MH. The sources and mechanisms of bioactive ingredients in coffee. Food Funct. 2019. 10:31133126.

Kazeem MI, Adamson JO, Ogunwande IA. Modes of inhibition of $\alpha$-amylase and $\alpha$-glucosidase by aqueous extract of Morinda lucida Benth leaf. Biomed Res Int. 2013. 2013:527570. https:// doi.org/10.1155/2013/527570

Kim JH, Kim HJ, Park HW, Youn SH, Choi DY, Shin CS. Development of inhibitors against lipase and $\alpha$-glucosidase from derivatives of monascus pigment. FEMS Microbiol Lett. 2007. 276:93-98.

Kirana C, Rogers PF, Bennett LE, Abeywardena MY, Patten GS. Naturally derived micelles for rapid in vitro screening of potential cholesterol-lowering bioactives. J Agric Food Chem. 2005. 53:4623-4627.

Kobayashi M, Ikeda I. Mechanisms of inhibition of cholesterol absorption by green tea catechins. Food Sci Technol Res. 2017. 23:627-636.

Kumar K, Srivastav S, Sharanagat VS. Ultrasound assisted extraction (UAE) of bioactive compounds from fruit and vegetable processing by-products: a review. Ultrason Sonochem. 2021. 70:105325. https://doi.org/10.1016/j.ultsonch.2020.105325

Liu CW, Wang YC, Huang CY, Lu HC, Chiang WD. Optimization extraction conditions with ultrasound for anti-hyperglycemic activities from Psidium guajava leaf. Food Sci Technol Res. 2015. 21:615-621.

Liu S, Ai Z, Qu F, Chen Y, Ni D. Effect of steeping temperature on antioxidant and inhibitory activities of green tea extracts against $\alpha$-amylase, $\alpha$-glucosidase and intestinal glucose uptake. Food Chem. 2017. 234:168-173.

Liu TT, Liu XT, Chen QX, Shi Y. Lipase inhibitors for obesity: a review. Biomed Pharmacother. 2020. 128:110314. https://doi. org/10.1016/j.biopha.2020.110314

Murase T, Yokoi Y, Misawa K, Ominami H, Suzuki Y, Shibuya Y, et al. Coffee polyphenols modulate whole-body substrate oxidation and suppress postprandial hyperglycaemia, hyperinsulinaemia and hyperlipidaemia. Br J Nutr. 2012. 107:1757-1765.

Nelson L, Perrone J. Herbal and alternative medicine. Emerg Med Clin N Am. 2000. 18:709-722.

Noor Aliah AM, Fareez Edzuan AM, Noor Diana AM. A review of quality coffee roasting degree evaluation. J Appl Sci Agric. 2015. 10:18-23.

Nordestgaard AT, Thomsen M, Nordestgaard BG. Coffee intake and risk of obesity, metabolic syndrome and type 2 diabetes: a Mendelian randomization study. Int J Epidemiol. 2015. 44: 551-565

Pittia P, Dalla Rosa M, Lerici CR. Textural changes of coffee beans as affected by roasting conditions. LWT-Food Sci Technol. 2001. 34:168-175.

Quan NV, Xuan TD, Tran HD, Thuy NTD, Trang LT, Huong CT, et al. Antioxidant, $\alpha$-amylase and $\alpha$-glucosidase inhibitory activities and potential constituents of Canarium tramdenum Bark. Molecules. 2019. 24:605. https://doi.org/10.3390/molecules 24030605

Quintero Quiroz J, Naranjo Duran AM, Silva Garcia M, Ciro Gomez GL, Rojas Camargo JJ. Ultrasound-assisted extraction of bioactive compounds from annatto seeds, evaluation of their antimicrobial and antioxidant activity, and identification of main compounds by LC/ESI-MS analysis. 2019. 2019:3721828. https://doi.org/10.1155/2019/3721828

Rasouli H, Hosseini-Ghazvini SM, Adibi H, Khodarahmi R. Differential $\alpha$-amylase/ $\alpha$-glucosidase inhibitory activities of plantderived phenolic compounds: a virtual screening perspective for the treatment of obesity and diabetes. Food Funct. 2017. 8:1942-1954.

Shang F, Li X, Jiang X. Coffee consumption and risk of the metabolic syndrome: a meta-analysis. Diabetes Metab. 2016. 42: 80-87.

Sultana R, Alashi AM, Islam K, Saifullah M, Haque CE, Aluko RE. Inhibitory activities of polyphenolic extracts of Bangladeshi vegetables against $\alpha$-amylase, $\alpha$-glucosidase, pancreatic lipase, renin, and angiotensin-converting enzyme. Foods. 2020. 9:844. https://doi.org/10.3390/foods9070844

van de Laar FA, Lucassen PL, Akkermans RP, van de Lisdonk EH, Rutten GE, van Weel C. $\alpha$-Glucosidase inhibitors for patients with type 2 diabetes: results from a Cochrane systematic review and meta-analysis. Diabetes Care. 2005. 28:154-163.

Vignoli JA, Viegas MC, Bassoli DG, Benassi MT. Roasting process affects differently the bioactive compounds and the antioxidant activity of arabica and robusta coffees. Food Res Int. 2014. 61:279-285.

Woollett LA, Wang Y, Buckley DD, Yao L, Chin S, Granholm N, et al. Micellar solubilisation of cholesterol is essential for absorption in humans. Gut. 2006. 55:197-204.

Yamanashi Y, Takada T, Suzuki H. Niemann-Pick C1-like 1 overexpression facilitates ezetimibe-sensitive cholesterol and $\beta$-sitosterol uptake in CaCo-2 cells. J Pharmacol Exp Ther. 2007. 320:559-564.

Zhang J, Sun L, Dong Y, Fang Z, Nisar T, Zhao T, et al. Chemical compositions and $\alpha$-glucosidase inhibitory effects of anthocyanidins from blueberry, blackcurrant and blue honeysuckle fruits. Food Chem. 2019. 299:125102. https://doi.org/10. 1016/j.foodchem.2019.125102 